DOCTRINA

\title{
El balanceo constitucional y la aplicación del método de proporcionalidad en las encuestas electorales
}

\author{
The constitutional balance and the application \\ of the proportionality method in the electoral surveys
}

Jorge Ricardo Palomares García

Universidad Libre, Colombia

\begin{abstract}
RESUMEN El presente artículo tiene como objeto determinar la posibilidad de reglamentar las encuestas electorales en Colombia. Para ello se aborda, desde la metodología de la línea jurisprudencia y de la dogmática jurídica, cuáles serían las normas legislativas que, por una parte, respetasen la libertad de opinión e información y, por otra parte, se desarrollen dentro de la función legislativa y el límite de información veraz.
\end{abstract}

PALABRAS CLAVE Encuestas electorales, derechos fundamentales, función electoral, método de proporcionalidad.

ABSTRACT This paper analyses the possibility of applying rules to the election polls in Colombia. For this, we question, from the methodology of judiciary line and judiciary dogma, which would be the legal norms that, on hand, respect the freedom of speech and information, and, on the other hand, work inside the electoral State function and truthful information.

KEYWORDS Election polls, civil rights, electoral state functions, proportionality method.

\section{Introducción}

El presente artículo es resultado del proyecto de investigación titulado «Transformación de la hermenéutica constitucional e influjo de la doctrina en las sentencias de la Corte Constitucional: 1992-2015", aprobado por el Centro de Investigaciones Sociojurídicas y financiado por la Universidad Libre, seccional Bogotá. En especial, este artículo es resultado del objetivo de determinar cómo la doctrina jurídica influ- 
ye en la construcción y aplicación de los métodos conflictualistas en la jurisprudencia constitucional colombiana, especialmente en los métodos de proporcionalidad e igualdad.

El objeto principal de este artículo es determinar cómo la Corte Constitucional, a partir de situaciones concretas, construye un razonamiento para aplicar el método de proporcionalidad. Para ello, se tomó un caso práctico, a saber, la facultad estatal de reglamentación y restricción de realización y divulgación de encuestas electorales en Colombia. A través de esta problemática, se reconocieron los patrones fácticos de las encuestas electorales en el país, especialmente en las contiendas electorales del 2015, que han revivido la pregunta sobre los límites éticos y jurídicos de la publicación de intenciones de voto y sus efectos normativos y prácticos en las campañas electorales. Estos patrones, a su vez, se revisaron a partir de un estado del arte, no exhaustivo, sobre las cuestiones constitucionales que implican una posible reglamentación de la realización y divulgación de encuestas electorales.

A partir de estos dos elementos, se reconstruyó el pensamiento o balanceo constitucional de la Corte Constitucional en materia de encuestas electorales y se identificó el método aplicado por la misma para establecer cuándo una reglamentación o restricción de esta función electoral implica una vulneración de los derechos fundamentales. Este ejercicio permitió establecer que, en materia de funciones electorales, la Corte Constitucional emplea el método de proporcionalidad. Sin embargo, este método tuvo modificaciones en la asignación de valores, a medida que las reglamentaciones anteriores al proyecto de ley propuesto por el Congreso a finales de este año cambiaban la intensidad de las reglas o restricciones.

En este sentido, el artículo se estructura en cuatro partes. La primera consiste en una descripción de la problemática colombiana en torno a las encuestas electorales, especialmente en las realizadas en las campañas electorales del 2015, para llegar a la pregunta de si el Estado está facultado para reglamentar las funciones electorales, especialmente aquellas ligadas con las metodologías empleadas por las encuestas y las formas de divulgación de las mismas. En este mismo apartado se explora un estado del arte, que permite comprobar cómo estas problemáticas, que se han presentado en otros contextos, han sido tratadas por otros autores y ordenamientos jurídicos. En el segundo apartado se exponen las metodologías empleadas en la investigación, la cual permitió establecer que el método dominante en el examen de constitucionalidad es la proporcionalidad. Asimismo, se explica cómo se construye este método y cuáles son sus pasos. En el tercer apartado se presentan los resultados obtenidos de la aplicación de esta metodología, a través de la identificación de reglas y sub-reglas, así como de la aplicación del método de proporcionalidad en dos momentos. Finalmente se presentan algunas conclusiones, que se contrastan con el proyecto de ley propuesto por el Congreso de la República. 


\section{Consideraciones generales}

\section{Planteamiento de problema}

La Corte Constitucional, desde su primer fallo sobre encuestas electorales, planteó dos problemas hipotéticos, que debían considerarse en la fundamentación constitucional de esta función electoral. El primer problema consiste en que las elecciones pueden correr el riesgo de ser realizadas por agentes no idóneos o, por agentes idóneos pero con metodologías (sondeos) errados. El segundo problema hipotético consiste en que las encuestas -así hayan sido realizadas correctamente-, pueden ser objeto de interpretaciones tendenciosas por parte de los medios de comunicación. ${ }^{1}$

La Corte Constitucional, sin embargo, sólo reflexionó las posibles consecuencias normativas de dichos problemas, sin entrar — debido a su límite competencial- en las consecuencias fácticas de los problemas hipotéticos. La consecuencia normativa, de acuerdo a la Corte Constitucional, consiste en la vulneración del límite del derecho a informar, el cual consiste en la transmisión de contenidos veraces. ${ }^{2}$

La preocupación sobre la concreción de estos problemas hipotéticos en los escenarios políticos colombianos surgieron nuevamente en las elecciones populares de entes territoriales - alcaldías y gobernaciones, así como concejos municipales y asambleas departamentales - en el 2015. La razón de este resurgimiento radica en la discrepancia entre las encuestas realizadas por unas compañías y las realizadas por otras, cuyo margen de diferencia era significativo. Dicha discrepancia se percibió en las encuestas realizadas por las compañías Cifras \& Conceptos, Gallup, Datexco y Centro de Consultoría Nacional.

Cifras \& Conceptos realizó varias encuestas. La primera fue entre el 7 y 12 de septiembre, ${ }^{3}$ la segunda entre el 30 de septiembre y 5 de octubre ${ }^{4}$ y la tercera entre el 15 y 20 de octubre..$^{5}$ Estas encuestas se caracterizaron por tener como población definida hombres y mujeres, mayores de 18 años, que hayan votado al menos una vez en los últimos cinco votos, con una metodología de entrevista cara a cara. El resultado de estas encuestas reflejó una intención permanente de voto, con un crecimiento progresivo en cada candidato. Por ejemplo, Enrique Peñalosa obtuvo una intención de voto de $23 \%$, 22\% y 26\%; Rafael Pardo obtuvo una intención de voto de $20 \%, 22 \%$ y 24,7\%; mientras que Clara López obtuvo una intención de voto de $17 \%, 19 \%$ y 21,3\%.

La segunda compañía encuestadora fue el Centro Nacional de Consultoría, que

1. Sentencia de Jesús Pérez González-Rubio con CongRep (artículo 23 inciso 2 Ley 58/1985), Corte Constitucional de Colombia, rol C 488/1993, expediente D-272.

2. Sentencia de constitucionalidad de Jesús Pérez González-Rubio con CongRep.

3. Cifras \& Conceptos, «Septiembre 2015: Elecciones alcaldías», disponible en http://bit.ly/2DmRzHj.

4. Cifras \& Conceptos, «Octubre 2015: Elecciones alcaldías», disponible en http://bit.ly/2DmWFmB.

5. Cifras \& Conceptos, «Octubre 2015: Elecciones alcaldías», disponible en http://bit.ly/2Doabq2. 
realizó cinco mediciones: la primera el 27 de agosto de 2015, la segunda el 17 de septiembre, la tercera 12 de octubre, la cuarta el 19 de octubre y la quinta el 23 de octubre. ${ }^{6}$ Estas encuestas se caracterizaron por tener como población definida los hombres y las mujeres, mayores de 18 años, residentes en la zona urbana y con intención de votar, y se empleó una metodología mixta, compuesta por encuestas presenciales o cara a cara y por encuestas telefónicas. El resultado de estas encuestas fue una intención de voto con intenciones crecientes y decrecientes de los candidatos. Enrique Peñalosa obtuvo una intención de voto de $27 \%, 34 \%, 31 \%, 30 \%$ y $29 \%$; Rafael Pardo obtuvo una intención de voto de $22 \%, 22 \%, 24 \%, 24 \%$ y $23 \%$; mientras que Clara López obtuvo una intención de voto de $17 \%, 14 \%, 19 \%, 20 \%$ y $19 \%$.

La tercera compañía encuestadora fue Invamer-Gallup que, entre otras, realizó dos mediciones, las cuales fueron analizadas por el Instituto de Estudios Urbanos (IEU), de la Universidad Nacional: la primera es del 6 de mayo del 2015, ${ }^{7}$ mientras que la segunda es del 22 de octubre. ${ }^{8}$ La población definida para estas encuestas fueron hombres y mujeres, mayores de 18 años, aptas para votar. El resultado de las encuestas fue una intención de voto creciente para algunos candidatos. Enrique Peñalosa obtuvo una intención de voto de 12,3\% y 32,1\%; Rafael Pardo obtuvo una intención de voto de $26,8 \%$ y $28 \%$; mientras que Clara López obtuvo una intención de voto de $24 \%$ y $20 \%$.

La cuarta compañía encuestadora fue Datexco, que realizó cuatro mediciones: la primera fue 21 de mayo del $2015,{ }^{9}$ la segunda el 13 de agosto, ${ }^{10}$ la tercera el 2 de octubre $^{11}$ y la cuarta el 24 de octubre. ${ }^{12}$ Estas encuestas se caracterizaron por tener como población definida los hombres y mujeres, mayores de 18 años, que manifestaron su intención de votar, y la metodología encuesta telefónica orientada por directorios telefónicos. El resultado de las encuestas fue un crecimiento progresivo en la intención de voto respecto a algunos candidatos. Enrique Peñalosa obtuvo una intención de voto de 21,8\%,31,4\%, 22,4\% y 33,9\%; Rafael Pardo obtuvo una intención de voto de

6. Centro Nacional de Consultoría, «Elecciones 2015: Así va la intención de voto», disponible en http:// bit.ly/2DlZhkS.

7. Instituto de Estudios Urbanos, «Análisis general de los resultados de la encuesta Invamer Gallup sobre las elecciones de alcaldes: Empieza la carrera política», Debates Gobierno Urbano, junio de 2015, disponible en http://bit.ly/2DnWOgD.

8. Instituto de Estudios Urbanos, «Elecciones regionales 2015», Debates de Gobierno Urbano, octubre de 2015, disponible en http://bit.ly/2DkTqfq.

9. «Bogotá: Peñalosa lidera con 21,8\% intención de voto para la alcaldía de Bogotá», El Tiempo.

10. «Peñalosa adelanta a Pardo en intención de voto para Alcaldía de Bogotá», La W, 14 de agosto de 2015, disponible en http://bit.ly/2DlZAfo.

11. Ernesto Cortés Fierro, «Se apretó la campaña en Bogotá, revela nueva encuesta», El Tiempo, 3 de octubre de 2015, disponible en http://bit.ly/2DojyGp.

12. «Bogotá: Peñalosa 33,9\%, Pardo 21,3\%, Clara López 15,4\% y F. Santos 8,4\%», El Tiempo. 
$18,5 \%, 28 \%, 16,5 \%$ y 21,3\%; mientras que Clara López obtuvo una intención de voto de $16,7 \%, 10,3 \%$ y $15,4 \%$ (en agosto no fue medida la intención de voto respecto a esta candidata).

Si bien las encuestas no se equivocaron en cuanto a la proyección del alcalde electo, la discusión se presentó porque los resultados entre unas encuestas y otras divergían significativamente. En mayo y agosto, la diferencia entre una encuesta y otra era mayor a cuatro puntos para todos los candidatos; en septiembre, la diferencia se redujo aproximadamente a tres puntos, como muestra la tabla 1.

Tabla 1. Comparativo de resultados de encuestas primeros meses

\begin{tabular}{|c|c|c|c|c|c|c|c|c|c|c|c|c|}
\hline & \multicolumn{4}{|c|}{ Mayo } & \multicolumn{4}{|c|}{ Agosto } & \multicolumn{4}{|c|}{ Septiembre } \\
\hline & $C \& C$ & CNC & Gall & Dat & $C \& C$ & CNC & Gall & Dat & $C \& C$ & CNC & Gall & Dat \\
\hline Peñalosa & & & 12,3 & 21,8 & & 27 & & 31,4 & 23 & 34 & & \\
\hline Pardo & & & 26,8 & 18,5 & & 22 & & 28 & 20 & 22 & & \\
\hline López & & & 24 & 16,7 & & 17 & & 10,3 & 17 & 14 & & \\
\hline
\end{tabular}

En octubre, por otro lado, las diferencias oscilaban entre más de seis puntos (octubre 1) y más de cinco puntos (octubre 2), como muestra la tabla 2.

Tabla 2. Comparativo resultados octubre

\begin{tabular}{|c|c|c|c|c|c|c|c|c|}
\hline \multirow[b]{3}{*}{ Peñalosa } & \multicolumn{4}{|c|}{ Octubre 1} & \multicolumn{4}{|c|}{ Octubre 2} \\
\hline & $C \& C$ & CNC & Gall & Dat & $C \& C$ & CNC & Gall & Dat \\
\hline & 22 & 30 & & 22,4 & 26 & 29 & 32,1 & 33,9 \\
\hline Pardo & 22 & 24 & & 16,5 & 24,7 & 23 & 28 & 21,3 \\
\hline López & 19 & 20 & & 10,3 & 21,3 & 19 & 20 & 15,4 \\
\hline
\end{tabular}

Aunque las firmas encuestadoras sostuvieron que los márgenes de diferencia son posibles, si se tiene en cuenta las metodologías, las divergencias que se presentaron provocaron dos efectos en las contiendas electorales. Por un lado, los candidatos cuestionaron la idoneidad de las encuestas, bien por reflejar una posible guerra sucia, como fue el caso de la carta de la candidata Clara López, en que cuestiona la metodología mal empleada intencionalmente por parte de Datexco. ${ }^{13}$ Asimismo, se cuestionó la elaboración de las metodologías por aparente vinculación de los directivos de las firmas con candidatos electorales, como fue el caso de César Caballero. ${ }^{14}$ Por otro lado, el Consejo Nacional Electoral intervino la realización de las encuestas electorales, mediante la expedición de la Circular Externa 002/2015, la cual recuerda

13. «Tire y afloje entre Clara López y Datexco por última encuesta», El Tiempo, 5 de octubre de 2015, disponible en http://bit.ly/2DmHvxW.

14. Juanita León, ««Yo respeto mis datos»: César Caballero», La Silla Vacía, 4 de octubre de 2015, disponible en http://bit.ly/2DooydY. 
las obligaciones de las firmas encuestadoras respecto a la realización de encuestas prelectorales.

Esta situación llevo al Congreso a proponer un proyecto de ley 114/2015 (Senado), a través del cual se crean disposiciones para la realización y divulgación de encuestas electorales. Entre estas disposiciones se encuentran, entre otros, la restricción de emplear medios telefónicos o internet para la realización de encuestas, así como la prohibición de realizar y divulgar encuestas durante los siete días previos a la elección popular. Por ello, la pregunta a responder, ante el proyecto de ley, consiste en si el Estado está facultado para reglamentar las fases y técnicas de realización y divulgación de encuestas, así como cuáles son los límites a esta facultad. Para ello, se revisará el estado del arte y el balanceo jurisprudencial hecho por la Corte Constitucional en la materia.

\section{Estado del arte en materia de regulación de encuestas electorales}

La literatura ha abordado el tema de las encuestas electorales desde tres enfoques. El primero de ellos consiste en lo que podría denominarse «enfoque esencial», y se caracteriza, principalmente, en abordar aspectos tales como la definición misma del término «encuesta electoral», así como su relación directa con el principio democrático. El segundo enfoque podría denominarse «estructuralista» y se caracteriza por los cuestionamientos que hacen los autores, no respecto del concepto mismo de encuesta y su relación con la democracia, sino con las etapas de la realización de encuestas electorales, así como los problemas que se pueden presentar si los aspectos metodológicos de las encuestas no son abordados correctamente. El tercer enfoque podría denominarse «funcional» y se caracteriza por las discusiones que plantean los autores en torno a la pregunta de si una encuesta electoral tiene una función de predicción o simplemente de descripción de tendencias pasadas, y cuáles son los alcances de cada función.

Desde el enfoque esencial de las encuestas electorales, los autores han sostenido un acuerdo - no muy desarrollado-. Éste consiste en que las encuestas electorales reflejan una transición de regímenes autoritarios hacia sistemas políticos con un amplio margen de participación de distintos actores (Gálvez Muñoz, 2000: 97 y ss.; Pacheco Luna y Velásquez Posada, 2006: 54). Sin embargo, las encuestas electorales reflejan, a su vez, un peligro, pues ellas pueden constituirse en herramientas de difusión de subjetividades (Gálvez Muñoz, 2000: 100) o de manipulación de información (Pacheco Luna y Velásquez Posada, 2006: 54).

Bajo estos escenarios, la literatura se ha cuestionado sobre el concepto de encuesta y cuál es el margen de actuación estatal de restricción de la realización de encuestas electorales. Uno de los autores que se aborda estos interrogantes es Valdez, para quien las encuestas o sondeos electorales no deben entenderse únicamente como una me- 
dición, de carácter científico, de las actitudes políticas, sino como una herramienta, en la que convergen, además de la opinión del electorado, intereses económicos en juego y réditos políticos, que dependen de la publicación de las encuestas electorales (Gálvez Muñoz, 2000: 101). A partir de esta aclaración, Valdez dedica su estudio para cuestionar la tesis de la marginalidad y plantea, entre otros, los siguientes puntos: a) la disminución de encuestas electorales por una lógica de mercado competitivo imagen de la empresa encuestadora- es un argumento débil (Gálvez Muñoz, 200o: 107), pues las empresas encuestadoras pueden nacer y liquidarse, así como mutar, sin mayores complicaciones (Gálvez Muñoz, 2000: 109) y; b) la imposibilidad de prever la dirección de la influencia de las encuestas es insuficiente, pues una encuesta manipulada puede alterar efectivamente el comportamiento ciudadano (Gálvez Muñoz, 2000: 112), así no coincida con los resultados electorales (por ejemplo, a través de la teoría de la espiral de silencio, enunciada en diversas obras).

Otros autores, como Pacheco Luna y Velásquez Posada, sostienen que las encuestas son un concepto sobredimensionado, pues ellas deben entenderse, en realidad, como un instrumento de diagnóstico que permite conocer la modificación y consolidación de tendencias electorales (Pacheco Luna y Velásquez Posada, 2006: 55). Sin embargo, los autores reconocen, a partir de un dato estadístico, que las encuestas electorales logran cierto «ruido» en el comportamiento social y que, en la actualidad, se ha presentado el riesgo de difundir encuestas electorales, a través de los medios de comunicación, sin tener certeza sobre su autenticidad y calidad (Pacheco Luna y Velásquez Posada, 2006: 56). Asimismo, los autores reconocen los problemas de las encuestas electorales y su influencia sobre el comportamiento del electorado (Pacheco Luna y Velásquez Posada, 2006: 56). A partir de estas preocupaciones, los autores realizan un estudio de derecho comparado, en el cual se cuestionan cómo las preocupaciones son abordadas por distintos ordenamientos jurídicos. Este estudio se realiza a partir de unos requisitos comunes - transparencia de las encuestas, tiempos de restricción, sistemas de fianza, protección de datos, etcétera-, y llegan, entre otras, a las siguientes conclusiones (Pacheco Luna y Velásquez Posada, 2006: 72 y ss.): a) las encuestas deben regirse por el principio de transparencia, no sólo en la metodología, sino también en la entrega y difusión de las mismas; b) las opiniones expresadas en las encuestas son comentarios y no afirmaciones contundentes, y c) el Estado no debe imponer reglas metodológicas, sino establecer criterios generales que permitan la elección de metodologías adecuadas.

El enfoque «estructuralista» no se preocupa por las cuestiones en torno a la definición o concepción de las encuestas electorales, así como su relación con la democracia. Este enfoque se centra, por el contrario, en dos aspectos. El primero de ellos consiste en determinar cómo el indebido empleo de metodologías - así como sus pasos- puede producir imprecisiones en la publicación de resultados y, por tanto, repercusiones no deseadas. El segundo aspecto consiste en cuestionar si la imposición 
de reglas estatales sobre elementos - o momentos- de la realización de encuestas electorales puede significar la restricción injustificada de derechos fundamentales.

Bajo el primer aspecto, diversos autores han revisado la metodología de las encuestas electorales, bien en su totalidad o bien en algún elemento concreto. Ejemplo de revisiones completas de la metodología de las encuestas electorales puede encontrarse en el trabajo de Moreno, Aguilar y Romero (2011). Estos autores se cuestionaron por qué las encuestas preelectorales no coincidieron con las elecciones para gobernadores en el 2010 en Venezuela. Para ello, revisaron varios aspecto del levantamiento de encuestas y llegaron, entre otros, a los siguientes resultados: a) las encuestas preelectorales fallaron en la descripción de datos sobre los votantes probables, es decir, no hubo un análisis sobre las variables de motivación individual, de motivación familiar o social y de preferencia del voto anterior (Moreno, Aguilar y Romero , 2011: 19-26); b) la indebida ubicación de la pregunta de intención puede afectar la precisión de las estimaciones de la encuesta (Moreno, Aguilar y Romero, 2011: 28 y ss.); c) la no consideración de la espiral de silencio implica variaciones en la estimaciones electorales — consideración de postura minoritaria-, y d) el diseño y aplicación de la encuesta puede influir en la decisión de quien opina, en especial si no se tienen en cuenta elementos tales como el perfil del encuestador, la supervisión y el diseño de las preguntas (Moreno, Aguilar y Romero, 2011: 31-41).

Otro ejemplo de revisión completa es el estudio de Nicodemo (2007), quien se pregunta también las razones de imprecisión de las encuestas electorales. Desde una perspectiva general, el autor establece las fallas de las encuestas desde dos momentos: a) el diseño y aplicación de las encuestas electorales, y b) la difusión, a través de medios de comunicación, de las encuestas electorales. En el primer momento, a semejanza de Moreno, Aguilar y Romero, Nicodemo reconoce que las encuestas pueden fallar si no se tienen en cuenta aspectos relevantes como la rigurosidad metodológica, los tamaños de la muestra, el fenómeno del azar y el comportamiento de último momento del elector (Nicodemo, 2007: 62), así como el error conceptual de la cobertura geográfica (Nicodemo, 2007: 63): inferir que la población tomará una decisión $x$ porque en ciertas ciudades, sin comprobar su grado de representatividad, optan por esa alternativa. Para responder a estas preocupaciones, Nicodemo identifica, en el caso venezolano, los abordajes hechos a las encuestas electorales, fundamentados en investigaciones cualitativas (Nicodemo, 2007: 63). Estos abordajes, a su vez, se clasifican de acuerdo al momento electoral y se entienden de la siguiente forma (Nicodemo, 2007: 63): a) antes del inicio de las campañas electorales, deben realizarse encuestas de diagnóstico, encuestas de selección de candidato, encuestas de audiencias y encuestas pre-test-publicitarias; b) durante las campañas electorales, se deben realizar encuestas post-test-publicitarias, encuestas de propósito múltiple, encuestas de gira de candidato, encuestas flash y encuestas fracking; c) durante las elecciones se realizarían encuestas de conteo de votos y encuestas voz a voz, y d) después de las 
elecciones se realizarían encuestas evaluativas y encuestas de gestión gubernamental. Esta clasificación, sin embargo, se rige por dos máximas. La primera consiste en que la realización de encuestas debe estar encabezada —a semejanza de Gálvez Muñoz-, por entidades especializadas (Nicodemo, 2007: 67); mientras que la segunda consiste en el correcto uso de muestreo probabilístico (Nicodemo, 2007: 67).

Por otra parte, el número de autores que abordan aspectos estructurales concretos es más amplio. Un primer aspecto es el diseño muestral, el cual es trabajado por Pavía y García-Cáceres (2012). En su estudio, los autores reconocen que un problema común en las encuestas del CIS consiste en la no coincidencia entre los tamaños de las poblaciones residentes y electorales (Pavía y García-Cáceres, 2012: 52), lo cual implicaría que extranjeros y menores de edad sean seleccionados en la muestra. Un segundo aspecto es el lugar de aplicación de la encuesta. Éste fue estudiado por Ortiz Lazcano (2006), quien sostiene que la determinación de la cultura política depende del factor geográfico y socioeconómico, pues ellos pueden influir -o cambiar, en términos del autor - en la forma de entender y discutir el fenómeno político (Ortiz Lazcano, 2006: 184). Un tercer aspecto consiste en la prohibición de realización y publicación de encuestas en días anteriores a las elecciones. Esta cuestión ha sido abordada, entre otros, por dos autores. El primero es Corzo Sosa (2007), mientras que el segundo es Fernández Sanabria (2010). Ambos autores estudian las críticas en torno al carácter manipulable de las encuestas electorales, así como los riesgos que implican en el electorado las encuestas manipuladas o malinterpretadas, y sostienen que dichos criterios son, en realidad, argumentos débiles (Corzo Sosa, 2007: 79; Fernández Sanabria, 2010: 8 y ss.). Por otra parte, sostienen que, en realidad, la imposición de cualquier restricción temporal a la realización y divulgación de encuestas electorales constituye una vulneración a los derechos de igualdad (Corzo Sosa, 2007: 79; Fernández Sanabria, 2010: 37 y ss.), libertad de información (Corzo Sosa, 2007: 79 y ss.; Fernández Sanabria, 2010: 37 y ss.) y libertad de expresión (Corzo Sosa, 2007: 81).

En cuanto al enfoque «funcional», los autores de este grupo se cuestionan cuál es la finalidad concreta de las encuestas electorales. Algunos, como Hernández Val$\mathrm{dez}$, sostienen que las encuestas electorales no son un instrumento predictivo, sino un instrumento que, en combinación con los medios de comunicación, influyen en las creencias y expectativas de los votantes (Hernández Valdez, 2013: 64 y ss.) y, por tanto, debería existir una regulación que garantice el carácter genuino del proceso deliberativo (Hernández Valdez, 2013: 74 y ss.). En una dirección similar se encuentra el estudio de Mateos y Penadés (2013), para quienes las encuestas no pueden obtener un carácter de predicción óptimo, sino que deben servir, a través de procesos de autorregulación y de regulación estatal, como instrumentos de autocrítica y reflexión respecto a los cambios en materia de intención de voto. 


\section{Metodología empleada}

Para responder al interrogante sobre la facultad constitucional del Estado para reglamentar las encuestas electorales en el sistema político colombiano, se emplearon dos metodologías: línea jurisprudencial y dogmática constitucional.

\section{Línea jurisprudencial}

El empleo de la línea jurisprudencial tuvo como objeto determinar la existencia de un balanceo constitucional sobre las encuestas electorales, es decir, un conjunto de reglas y subreglas jurisprudenciales - o doctrina jurisprudencial, en términos de López Medina (2014: 140) - que sirvan como criterio estándar de actuación, bien sea estatal (Legislador, Ejecutivo o jurisdicción) o particular (partidos políticos, medios de comunicación, litigio estratégico, etcétera).

Para realizar dicha metodología, se planteó como problema jurídico de carácter casuístico (López Medina, 2014: 150 y ss.) si el Estado está facultado para reglamentar el diseño, la aplicación y la divulgación de encuestas electorales en tiempos de campaña y elecciones. De esta pregunta, a su vez, se proyectaron los polos hipotéticos. El primero de ellos establece que el Estado no puede regular, en forma alguna, la realización de encuestas electorales, pues ello implicaría, además de una restricción indebida en las funciones electorales, una restricción a los derechos fundamentales de libertad de opinión y de libertad de información. Este polo hipotético se construyó a partir de la dimensión esencial del estado del arte, pues de acuerdo con algunos de los autores revisados, las encuestas electorales deben ser entendidas no como un mero ejercicio electoral, sino como el instrumento mediante el cual la ciudadanía expresa y forma su percepción sobre el funcionamiento del andamiaje político y electoral $y$, al ser desarrollo del ejercicio de opinión, cualquier restricción podría constituirse en nociva. El segundo polo hipotético establece que el Estado puede regular aspectos de la realización de campañas electorales, pues ello garantiza el ejercicio del derecho fundamental a votar sin presión alguna. Este polo se diseñó a partir de las dimensiones estructurales y funcionales del estado del arte, en las cuales se cuestionaba, por una parte, si las encuestas electorales podrían emplearse - bien mediante errores metodológicos o bien bajo otros factores - como elemento de campaña y, por otra parte, si las encuestas electorales podían influir o predecir los resultados electorales concretos. Esto aportó los elementos básicos para el diseño de la gráfica de balanceo constitucional presente en la figura 1. 
Figura 1. Esquema de balanceo constitucional.

\begin{tabular}{|ll|}
\hline Solución a & $\begin{array}{l}\text { Problema jurídico } \\
\text { ¿El Estado está facultado para reglamentar } \\
\text { el diseño, la aplicación y la divulgación } \\
\text { de encuestas electorales en tiempos de } \\
\text { campaña y elecciones? }\end{array}$ \\
\hline $\begin{array}{l}\text { El Estado no puede regular, en forma } \\
\text { alguna, la realización de encuestas elec- } \\
\text { torales, pues ello implicaría, además de } \\
\text { una restricción indebida en las funciones } \\
\text { electorales, una restricción a los derechos } \\
\text { fundamentales de libertad de información } \\
\text { y libertad de opinión. }\end{array}$ & $\begin{array}{l}\text { El Estado puede regular aspectos de la } \\
\text { realización de campañas electorales, pues } \\
\text { ello garantiza el ejercicio del derecho } \\
\text { fundamental a votar sin presión alguna. }\end{array}$ \\
\hline
\end{tabular}

El segundo paso consistió en identificar, a través de las bases de datos y del sistema de relatoría de la Corte Constitucional, la sentencia arquimédica, la cual debía caracterizarse por ser la más reciente y por contener el mismo patrón fáctico que el establecido por el problema de investigación (López Medina, 2014: 168) —expedición de leyes o decisiones estatales que reglamenten o restrinjan la realización de encuestas electorales-. Esta revisión permitió identificar, como fallo arquimédico, la sentencia de constitucionalidad C 1153/2005, cuyo hecho constitutivo fue la aprobación del proyecto de ley estatutaria 216/2005 (Senado) y 253/2005 (Cámara), mediante la cual se reglamenta la elección de presidente de la República, de conformidad con el artículo 152 literal $\mathrm{f}$ de la Constitución Política de Colombia y de acuerdo al Acto Legislativo 2 de 2004.

Este punto arquimédico, sin embargo, presenta dos problemas. El primero de ellos consiste en la fecha de la sentencia. Si se revisa con detenimiento, podría decirse que el punto arquimédico, pese a ser el más reciente, dista mucho, pues entre éste y el momento de proposición del proyecto de ley actual, han transcurrido aproximadamente diez años. Este lapso, a su vez, cuenta con la transición a una tercera Corte Constitucional, cuyos pensamientos u orientaciones pueden distar, tanto de la primera como de la segunda Corte Constitucional. Al no contar con un fallo reciente, que incluya las orientaciones conceptuales e ideológicas de la tercera Corte Constitucional, la línea jurisprudencial podría no ser coherente con un fallo próximo. Este problema, empero, puede responderse a través del argumento de estabilidad del precedente. Si bien la tercera Corte Constitucional no ha participado en la construcción de reglas y subreglas en materia de encuestas electorales, el concepto de precedente implica que las decisiones que ha tomado el guardián de la Constitución tienen vocación de permanencia. Ello significa que las decisiones tomadas por la Corte Constitucional no sólo implican un mandato hacia órganos estatales y jueces constitucionales a quo 
- carácter vertical del precedente-, sino también una vinculación a la misma Corte Constitucional - carácter horizontal del precedente-. Por tanto, la tercera Corte Constitucional se encontrará, en un caso similar futuro, ante dos situaciones: a) mantener los lineamientos establecidos por la línea jurisprudencial, a pesar de que su punto arquimédico diste bastante en el tiempo, o b) cuestionar la línea jurisprudencial existente, mediante las técnicas legítimas de interpretación de precedentes (López Medina, 2014: 213 y ss.). Asimismo, podría argumentarse —como se verá más adelante-, que los criterios mantenidos en el proyecto de ley se asemejan —en cierta medida - a los establecidos por la línea jurisprudencial y, por tanto, la Corte Constitucional, al revisar casos futuros sobre este proyecto, deberá revisarse a sí misma y, en consecuencia, a la línea jurisprudencial.

$\mathrm{El}$ segundo problema radica en la naturaleza del punto arquimédico. Al revisarse la metodología de línea jurisprudencial, su estudio pareciese iniciar por un punto arquímedico de naturaleza de amparo, es decir, pareciese recomendable que la primera sentencia - la más reciente - tenga como objeto una acción de tutela. Esta necesidad aparente se justifica en dos aspectos concretos. El primero de ellos consiste en que un fallo de tutela identifica y delimita adecuadamente un escenario constitucional mediante un patrón fáctico, mientras que una sentencia de constitucionalidad normativa estudia de forma abstracta, generalmente, la conformidad de la disposición constitucional con la disposición infraconstitucional, sin una concreción necesaria de patrones fácticos. El segundo aspecto consiste en que las sentencias de constitucionalidad abordan varios problemas jurídicos y, por tanto, varios escenarios constitucionales. Cada uno de estos escenarios constitucionales contará, en la sentencia de constitucionalidad, con varias reglas y subreglas - o varias ratio decidendi- que, si no son identificadas adecuadamente, pueden ser subsumidas en escenarios no correspondientes (por ejemplo, identificar como reglas de ratio de encuestas electorales reglas que en realidad corresponden a campañas políticas).

Para resolver este problema, se desestructuró el fallo a partir de los hechos complementarios. Por éstos se entendió cada apartado del proyecto de ley, que implicó la formulación de un interrogante concreto para la Corte Constitucional y, por tanto, de la construcción de una ratio decidendi autónoma y con la suficiente precisión para ser escindible de otros apartados. Ello permitió identificar que la Corte Constitucional dedicó, de forma sustancial, un apartado para las encuestas electorales, que se caracterizó por un diseño de lineamientos generales y por un estudio concreto de la compatibilidad normativa; ello puede verse en el número 4.2, literal e, subliteral g, titulado artículo 28 de las encuestas electorales.

Atendidos estos dos problemas, se realizó la ingeniería reversa, la cual consiste en el estudio de citas del punto arquimédico (López Medina, 2014: 170). Para ello, se descompuso el número 4.2, literal e, subliteral g, en los argumentos de obiter dictum y en la ratio decidendi, compuesta por las reglas, subreglas y argumentos de justifica- 
ción de las anteriores. Con esta descomposición, se pudo determinar cuáles eran las sentencias citadas en el reconocimiento de reglas y subreglas, las cuales son definidas por la metodología de la línea jurisprudencial como citas de primer nivel (López Medina, 2014: 171). Las citas identificadas fueron la sentencia de constitucionalidad C o89/1994 y la sentencia de constitucionalidad C 488/1993.

Luego de identificar estas sentencias, y después de resolver el problema de su naturaleza - ser sentencias de control abstracto-, se determinaros los apartados que trabajaban las encuestas electorales. Hecho esto, se distinguió entre argumentos de obiter dictum y ratio decidendi, para determinar cuáles eran las sentencias citadas en el diseño de reglas y subreglas de segundo nivel (López Medina, 2014: 172). El ejercicio permitió establecer que la sentencia de constitucionalidad C o89/1994 cita a la sentencia de constitucionalidad C 488/1993, mientras que ésta no cita sentencia alguna, como muestra la tabla 3 .

Tabla 3. Citaciones de sentencias

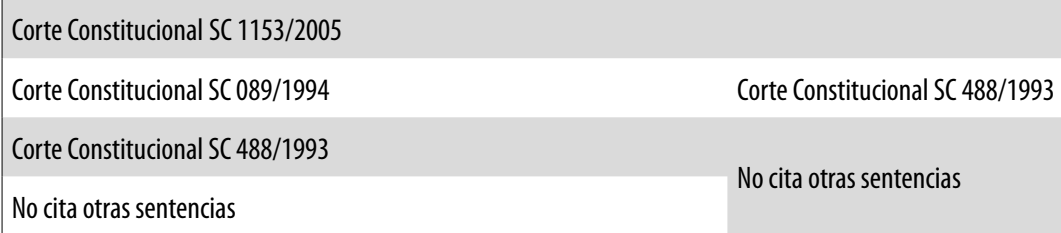

Con el primer y segundo nivel identificados, se procedió a la clasificación de las sentencias citadas (López Medina, 2014: 161), así como a la construcción del nicho citacional (López Medina, 2014: 173 y ss.), es decir, de las sentencias relevantes para la línea jurisprudencial.

La sentencia C 488/1993 es el caso Jesús Pérez González con CongRep (artículo 23 inciso 2 Ley 58 de 1985), cuyo hecho constitutivo fue la prohibición a todo medio de comunicación social de difundir, durante los treinta días anteriores a una elección, encuestas de opinión que muestren el grado de apoyo ciudadano a los candidatos o prevean el resultado de la elección. La pregunta que se formuló la Corte Constitucional en este caso consistió en si la prohibición de difusión de encuestas electorales por cualquier medio de comunicación social, durante los treinta días anteriores a la elección, podían constituir una vulneración a los derechos fundamentales de libertad de expresión y de libertad de información (derecho a informar y a recibir información). Tanto el hecho constitutivo como el problema jurídico son similares al problema de investigación planteado y se aproximan a uno de los polos hipotéticos. Por ello, podría considerarse que el caso Jesús Pérez González con CongRep, es una analogía cerrada y, por ello, una sentencia relevante para la línea jurisprudencial.

Por otra parte, el caso Jesús Pérez González con CongRep se caracteriza por ser un fallo que no contiene citación alguna, ni de autorreferenciación (sentencias de la mis- 
ma Corte Constitucional), ni de otro tipo. Lo más cercano a una citación consiste en la enunciación de John Stuart Mill para recalcar que la democracia no se limita al sistema de elecciones libres, sino que requiere participación, discusión, reflexión permanente sobre los asuntos públicos y para ello es necesaria la información. ${ }^{55}$ Este fallo, a su vez, se caracteriza por establecer lineamientos generales sobre cómo entender los derechos fundamentales de libertad de información y libertad de opinión, cuáles son sus núcleos esenciales y cómo surgen intromisiones desproporcionales. Estas dos características, junto con la de ubicarse en el período inicial de la Corte Constitucional, permiten clasificar esta sentencia como fundadora de línea (López Medina, 2014: 164).

La sentencia C 089/1994 es el caso CongRep («proyecto de ley 11/1992 Cámara, 348/1993 Senado, por medio del cual se dicta el Estatuto básico de partidos y movimientos políticos $[\ldots] »)$. Esta sentencia se caracteriza por reiterar las reglas en torno a la prohibición de publicar encuestas electorales durante los treinta días anteriores a la elección, consagradas en la sentencia de constitucionalidad C 488/1993, a través de una citación directa de esta sentencia. Sin embargo, mediante una argumentación sencilla, la Corte Constitucional reconoce que las encuestas electorales son objeto de reserva legal, bajo el criterio de prevención de instrumentación manipulativa y, por tanto, reconoce reglas de restricción en la realización de encuestas electorales. Por ello, esta sentencia podría ubicarse, en cierto sentido, bajo la categoría de sentencia consolidadora (López Medina, 2014: 164 y ss.).

La sentencia C 1153/2005, mencionada como punto arquimédico, tiene varias características. La primera de ellas consiste en que esta sentencia no se centra en la conceptualización de las encuestas electorales únicamente como expresión de los derechos fundamentales, sino como desarrollo del concepto función electoral. El desplazamiento conceptual le permitió a la Corte Constitucional reconocer la facultad de reglamentación de las encuestas electorales, no sólo desde la dimensión de su difusión - como era el caso de la sentencia C 488/1993-, sino también desde las dimensiones de agentes competentes (encuestadores) y de metodologías válidas. La segunda característica consiste en la redefinición del escenario constitucional. Mientras que las dos primeras sentencias abordaban las encuestas electorales en un escenario estable, la sentencia C 1153/2005 atendía un cambio constitucional: la reelección presidencial. Ante esta situación, la Corte Constitucional entendió el articulado completo como un instrumento de prevención ante posibles desequilibrios en las contiendas electorales cuando éstas tenían como candidato presidencial al presidente de la República en ejercicio. En otras palabras, la Corte Constitucional reinterpretó las encuestas electorales, a fin de que no se convirtiesen, a futuro, en instrumento propagandístico gubernamental. La tercera característica consiste en que la Corte Constitucional se aproxima, bajo una lectura del estado del arte, hacia una postura

15. Sentencia de constitucionalidad de Jesús Pérez González-Rubio con CongRep. 
estructuralista. Ello se refleja en que la Corte Constitucional parte de un intento de definición para, a partir de ella, identificar los elementos de la encuesta electoral y su grado de reglamentación. De acuerdo con estas características, podría decirse que la sentencia $C$ 1153/2005 es una sentencia reconceptualizadora (López Medina, 2014: 165).

Con las sentencias clasificadas, la metodología de la línea jurisprudencial indica que debe realizarse el balanceo constitucional, es decir, cuáles son las reglas y subreglas jurisprudenciales que se han mantenido en el tiempo. Sin embargo, para garantizar que la línea jurisprudencial estuviese completa, se optó por hacer un barrido de sentencias adicional. Este barrido consistió en establecer si existían sentencias que abordasen la reglamentación de encuestas electorales, que no fueron citadas por la sentencia arquimédica, ni por el primer o segundo nivel. En caso de existir dichas sentencias, debería preguntarse por qué no fueron citadas.

Este ejercicio permitió detectar dos fallos. El primero es la sentencia de constitucionalidad C 145/1994, mientras que el segundo es la sentencia de constitucionalidad C 353/1994. La sentencia C 145/1994 es el caso Jaime Orlando Santofimio con CongRep (Ley 84 de 1993), cuyo hecho constitutivo es la consagración de algunas disposiciones en materia electoral, y cuyo problema jurídico consistió en si el Congreso violó la reserva de ley estatutaria, al tratar temas electorales por vía de ley ordinaria. Si bien el hecho constitutivo y el problema jurídico pareciesen no abordar una analogía abierta o cerrada - con la pregunta de investigación, esta sentencia tiene dos características. La primera de ellas consiste en que la Corte Constitucional construye una analogía abierta, al invocar como regla de precedente aplicable a la prohibición de publicidad - de cualquier tipo- durante las veinticuatro horas anteriores a la elección la sentencia C 488/1993. La segunda característica consiste en que esta sentencia, a diferencia de las otras, establece la regla expresa de reserva de ley estatutaria para reglamentar las encuestas electorales. Por ello, aunque no es una sentencia que pueda ubicarse en el nicho citacional - por no ser referenciada por las otras sentencias-, puede ser tenida en cuenta en la línea jurisprudencial.

El segundo fallo es la sentencia C-353 de 1994, cuyo hecho constitutivo es la aprobación del proyecto de ley 214/1994 (Cámara) y 183/1994 (Senado), por medio de la cual se expiden algunas disposiciones en materia electoral. A diferencia de la sentencia C 145/1994, en este caso no se abordan las encuestas electorales como problema jurídico central, bien bajo la reserva estatutaria, ni bajo hechos complementarios, como se explicó antes. A su vez, esta sentencia aborda la cuestión de publicidad electoral, a la cual la Corte Constitucional le aplica, con cierta gradualidad, las reglas establecidas por las sentencias C 488/1993 y C o89/1994. Al no existir una analogía ni abordaje del problema de investigación, esta sentencia no es relevante en la línea jurisprudencial. Por tanto, el cuadro resultante podría presentarse como en la tabla 4. 
Tabla 4. Citaciones de sentencias.

\begin{tabular}{|l|l|l|}
\hline Corte Constitucional SC 1153/2005 & & \\
\hline Corte Constitucional SC 089/1994 & Corte Constitucional SC 145 1994 & Corte Constitucional SC 488/1993 \\
\hline Corte Constitucional SC 488/1993 & & No cita otras sentencias \\
\hline No cita otras sentencias & Corte Constitucional SC 488/1993 & \\
\hline
\end{tabular}

A partir de nicho citacional, se procedió a revisar cada una de las reglas y subreglas contenidas en cada decisión judicial y, con ellas, se estableció cómo entiende la Corte Constitucional las encuestas electorales y cuál es la facultad estatal para reglamentarlas. Este nicho citacional permitió establecer, también, que la Corte Constitucional ha considerado, desde su primer fallo hasta el punto arquimédico, una reglamentación de las encuestas electorales. Sin embargo, dicha reglamentación ha variado, pues en la sentencia fundadora de línea existía una interpretación rígida, que consideraba difícil una intervención estatal en las encuestas. Esto era así debido a que el eje gravitacional de la decisión se encuentra en la garantía de los derechos fundamentales de libertad de opinión y de libertad de información, los cuales no son reglamentables sino limitables al interactuar con otros derechos fundamentales. ${ }^{16}$ Este criterio cambió progresivamente hasta llegar al punto arquimédico. En esta sentencia, la facultad de reglamentación de las encuestas electorales se amplió porque, como se mencionó anteriormente, el eje gravitacional de la decisión se desplazó hacia el concepto de función electoral y su límite en el derecho fundamental a votar sin injerencia externa alguna. ${ }^{17}$ Ello permitiría graficar el balanceo constitucional como en la figura 2.

Figura 2. Esquema de balanceo constitucional

\begin{tabular}{|c|c|c|c|}
\hline Solución a & \multirow{2}{*}{\multicolumn{2}{|c|}{$\begin{array}{l}\text { Problema juridico } \\
\text { ¿El Estado está facultado para reglamentar el diseño, la aplicación } \\
\text { y la divulgación de encuestas electorales en tiempos de campaña y } \\
\text { elecciones? }\end{array}$}} & Solución b \\
\hline \multirow{5}{*}{$\begin{array}{l}\text { El Estado no puede regular, en } \\
\text { forma alguna, la realización de } \\
\text { encuestas electorales, pues ello } \\
\text { implicaría, además de una res- } \\
\text { tricción indebida en las funcio- } \\
\text { nes electorales, una restricción } \\
\text { a los derechos fundamentales } \\
\text { de libertad de información y de } \\
\text { libertad de opinión. }\end{array}$} & & & \multirow{5}{*}{$\begin{array}{l}\text { El Estado puede regular } \\
\text { aspectos de la realización } \\
\text { de campañas electorales, } \\
\text { pues ello garantiza el } \\
\text { ejercicio del derecho } \\
\text { fundamental a votar sin } \\
\text { presión alguna. }\end{array}$} \\
\hline & \multicolumn{2}{|l|}{$\begin{array}{l}\text { orte Constitucional } \\
\text { SC } 488 / 1993\end{array}$} & \\
\hline & \multicolumn{2}{|l|}{$\begin{array}{l}\text { Corte Constitucional } \\
\text { SC 089/1994 }\end{array}$} & \\
\hline & \multicolumn{2}{|r|}{$\begin{array}{l}\text { Corte Constitucional SC } \\
\text { 145/1994 }\end{array}$} & \\
\hline & \multicolumn{2}{|r|}{$\begin{array}{l}\text { Corte Constitucional SC } \\
1153 / 2005\end{array}$} & \\
\hline
\end{tabular}

16. Sentencia de constitucionalidad de Jesús Pérez González-Rubio con CongRep.

17. Sentencia de constitucionalidad de CongRep (proyecto de ley estatutaria 216/2005, Cámara, 235/2005, Senado), Corte Constitucional de Colombia, rol C 1153/2005, expediente PE-025. 


\section{Dogmática jurídica}

La construcción de la línea jurisprudencial implicó la necesidad de responder una pregunta adicional. Ella consiste en cómo varió la postura de la Corte Constitucional en torno al grado de intervención estatal en las encuestas electorales. Como los establece la metodología de la línea jurisprudencial, las variaciones en la postura de la Corte Constitucional sobre un aspecto determinado pueden darse a través de dos situaciones. La primera de ellas consiste en interpretaciones ilegítimas hechas por la Corte Constitucional - básicamente desconocimiento y desobediencia-, mientras que la segunda consiste en interpretaciones legítimas, como lo son, por ejemplo, las interpretaciones de las reglas de ratio y el cambio jurisprudencial.

En el caso presente de investigación, se descartaron las técnicas ilegítimas de interpretación, pues, al revisar la evolución de la línea jurisprudencial, se identificaron dos argumentos. El primero de ellos consiste en el reconocimiento permanente de las reglas de precedente. Desde el fallo arquimédio hasta la sentencia consolidadora, la Corte Constitucional ha reconocido como regla de precedente la sentencia de constitucionalidad C 488/1993 y ha mantenido su vigencia hasta el momento. El segundo argumento consiste en que, en ninguno de los fallos, la Corte Constitucional ha sostenido que las reglas concretas para determinar si una disposición que reglamente las encuestas electorales es inconstitucional o no deba desconocerse en casos presentes.

La variación de la gradualidad reglamentaria de las encuestas electorales se ubica, por tanto, en las técnicas de interpretación legítimas. En especial, la línea jurisprudencial varía a partir de la interpretación de las reglas de ratio. Ello puede reflejarse en dos aspectos concretos. El primero de ellos consiste en que la Corte Constitucional reconoce, en todas sus decisiones, la garantía de las libertades de expresión y de información. La Corte Constitucional, sin embargo, cambió su postura en torno a estos derechos, mediante una interpretación valorativa, caracterizada, inicialmente, por una fuerte fundamentación en la democracia participativa y, posteriormente, en fundamentación del ejercicio de la libertad, en especial de la autodeterminación electoral sin injerencia de otros factores, tales como la opinión ajena, la manipulación mediática, etcétera.

El segundo aspecto consiste en que la Corte Constitucional mantuvo, además de una interpretación valorativa de contenidos constitucionales, un criterio uniforme al momento de determinar, en concreto, si una disposición infraconstitucional de reglamentación de encuestas electorales constituía una vulneración de derechos fundamentales. Este criterio consistió en la aplicación de un método conflictualista, propio de la dogmática constitucional nacional y extranjera (Ibler, 2004: 22), denominado proporcionalidad. Por ello, en este apartado se explicará en qué consiste este método, mientras que en el próximo apartado se explicará cómo la Corte Constitucional aplicó este método a nuestra pregunta de investigación. 
Este método parte de tres supuestos. El primero consiste en que toda acción estatal está encaminada a satisfacer o garantizar un derecho fundamental o un principio es esencial. El segundo es que toda acción estatal, sin embargo, implica una restricción de otros derechos fundamentales (Bernal, 2009: 29). El tercero sostiene que, ante la colisión entre en un derecho fundamental no satisfecho y otro derecho fundamental que espera garantizarse, es necesario encontrar una solución que implique el menor sacrificio del primer derecho y una mayor garantía del segundo, sin caer en el diseño de un orden lexicográfico (Bernal, 2009: 29) de derechos (jerarquización), ni en una universalización de soluciones. Bajo estos tres supuestos, la literatura constitucional en general, y la Corte Constitucional en concreto, han diseñado un sistema de cuatro pasos para determinar si la acción estatal constituye una intervención proporcional en un derecho fundamental o no.

El primer paso consiste en determinar la existencia de un fin legítimo. Por él se entiende todo fin perseguido por el Estado que, por una parte, no contraríe la Constitución o la ley (Ibler, 2004: 23) y, por otro lado, garantice el goce, protección o cumplimiento de un derecho fundamental o de un principio fundante del Estado. De acuerdo a esta definición, algunos autores han sostenido que el fin legítimo debe revisarse desde dos dimensiones (Bernal, 2009: 49 y ss.): a) la dimensión inmediata del fin, que consiste en la persecución de metas fácticas, y b) la dimensión mediata del fin, que puede entenderse como la intención de garantía de bienes jurídicos constitucionales. Ejemplo de ello puede verse en el caso Paola Andrea Saavedra Hidalgo con CongRep (artículo 5 inciso 2 Ley 336/1996), en el cual la Corte Constitucional sostuvo que «una medida persigue un fin legítimo no sólo cuando hace efectiva la obligación estatal de reglamentar, regular o controlar una actividad [...] (fin inmediato), sino también salvaguardar los intereses de los diferentes actores [...], como de la comunidad en general (fin mediato)».

El segundo paso consiste en establecer la idoneidad de la medida estatal. Aquélla consiste en que la medida fomenta el fin el perseguido (Ibler, 2004: 24) o, en otras palabras, ofrece ayudas óptimas para alcanzar el fin. De acuerdo con la Corte Constitucional, el examen de este paso es de carácter excepcional, pues ello implica realizar un estudio de los efectos previsibles de la aplicación de la norma. ${ }^{18}$ Esto conlleva a considerar que el examen realizado en este paso es de plausibilidad, es decir, de pensar, en un marco de posibilidades, que la medida permite en cierto grado el fomento del fin.

El tercer paso consiste en comprobar la necesidad de la medida estatal. Por necesidad se entiende que la medida estatal adoptada garantice en mayor medida el derecho fundamental ${ }^{19} \mathrm{o}$ principio fundante del Estado objeto de protección y que,

18. Sentencia de constitucionalidad de Paola Andrea Saavedra Hidalgo con CongRep (artículo 5 inciso 2 Ley 336/1996), Corte Constitucional de Colombia, rol C 033/2014, expediente D-9753.

19. Sentencia de constitucionalidad de Miguel Antonio Rujana con CongRep (artículo zo literal b y c 
a su vez, implique la restricción menos gravosa del derecho fundamental afectado (Pieroth y otros, 2013: 69).

El cuarto paso es la proporcionalidad en estricto sentido. Este paso consiste en la aplicación de las reglas de ponderación (Bernal, 2009: 19 y ss.) que, de forma sintética - pues no es objeto de la investigación-, pueden describirse así: a) el operador jurídico debe identificar los contenidos constitucionales (derechos fundamentales o principios fundantes del Estado) que entran en colisión (Bernal, 2009: 30), a fin de someterlos a un ejercicio de comparación; b) posteriormente, se determina la importancia abstracta (peso abstracto) tanto del fin perseguido por el Estado, como del derecho fundamental restringido (Bernal, 2009: 24); c) identificada la importancia abstracta, se procede a establecer la importancia concreta en el caso, tanto del fin perseguido, como del derecho fundamental afectado, a través del grado de afectación de la acción estatal (peso concreto), y d) se determina la apreciación empírica de la afectación, es decir, se establece el grado de certeza respecto a la consecución del fin y de la restricción del derecho (Bernal, 2009: 40 y ss.). Estos pasos se resumen, como lo sostienen algunos autores, en la máxima de que cuan mayor sea la restricción o no satisfacción de un derecho fundamental, mayor deberá ser la necesidad de protección o satisfacción del otro derecho fundamental o principio fundante del Estado. La máxima se traduce, a su vez, en la siguiente fórmula (Breckwoldt y Kleiber, 2013: 10):

$$
G_{l, k}=\frac{G_{l} I_{l} S_{l}}{G_{k} I_{k} S_{k}}
$$

donde $l$ es el derecho fundamental afectado, mientras que $k$ es el Derecho fundamental o principio fundante del Estado perseguido; $G$ es el peso abstracto de los contenidos constitucionales, $I$ es el peso concreto y $S$ es el grado de certeza o nivel de seguridad (Breckwoldt y Kleiber, 2013: 10).

\section{Reglas constitucionales en materia de encuestas}

La Corte Constitucional es consciente de los problemas que pueden presentar las encuestas electorales en la democracia colombiana y, por tanto, ha construido una línea jurisprudencial uniforme sobre cómo debe entenderse el concepto de encuesta electoral, así como las funciones y límites que ella tiene en los procesos de toma de decisiones populares. Dicha línea jurisprudencial, a su vez, se rige sobre dos ejes fundamentales. El primero de ellos es el ejercicio de los derechos fundamentales de

Ley 1.493/2011), rol C 144/2015, expediente D-10347. 
participación política ${ }^{20} \mathrm{y}$ de información, ${ }^{21}$ mientras que el segundo es la garantía del derecho fundamental a votar libremente, es decir, sin injerencia alguna, ${ }^{22}$ así como del principio de transparencia en los procesos democráticos. ${ }^{23}$

Para la Corte Constitucional las encuestas electorales son encuestas de opinión pública, no científica, cuya finalidad es definir tendencias públicas, ${ }^{24}$ para el caso concreto, en materia electoral. Esta definición, en principio sencilla, contiene unos fines especiales, los cuales han sido reconocidos por la Corte Constitucional y agrupados por el primer eje definidor enunciados anteriormente.

El primer conjunto es de carácter político. En él, la Corte Constitucional ha identificado tres fines en concreto: ${ }^{25}$ a) la promoción de participación política de los aspirantes, pues las encuestas permiten conocer el ambiente político del país, así como la posibilidad que tiene un candidato potencial de participar en contiendas electorales; b) establecer la imagen pública de un candidato, su programa de gobierno y su popularidad, así como promover la transformación de propuestas políticas, y c) informar e influir en la opinión del electorado.

El segundo conjunto es la garantía de derechos fundamentales. La Corte Constitucional ha sostenido en especial que las encuestas electorales son un mecanismo mediante el cual los ciudadanos ejercen su derecho fundamental a expresar su opinión (derecho a dar a conocer la receptividad de los programas políticos). Asimismo, las encuestas electorales son un mecanismo que informan sobre las decisiones de los candidatos a cargos públicos sobre dicha receptividad. ${ }^{26}$

Estos fines indican que existe una obligación estatal de permitir la elaboración, implementación y difusión de encuestas electorales. Sin embargo, dichas acciones no son de libertad absoluta. De acuerdo a la línea jurisprudencial establecida por la Corte Constitucional, las encuestas electorales implican un riesgo y, por tanto, deben respetar un límite intrínseco. El riesgo consiste en que la encuestas, bien por el diseño

20. Sentencia de constitucionalidad de CongRep (proyecto de ley 214/1994, Cámara, 183/1994, Senado). 21. Sentencia de constitucionalidad de Jesús Pérez González-Rubio con CongRep.

22. Sentencia de constitucionalidad de CongRep (proyecto de ley estatutaria 11/1992, Cámara, 348/1993, Senado), rol C 089/1994, expediente PE o04.

23. Sentencia de constitucionalidad de CongRep (proyecto de ley estatutaria 216/2005, Cámara, 235/2005, Senado).

24. Sentencia de constitucionalidad de CongRep (proyecto de ley estatutaria 216/2005, Cámara, 235/2005, Senado).

25. Sentencia de constitucionalidad de CongRep (proyecto de ley estatutaria 216/2005, Cámara, 235/2005, Senado).

26. Sentencia de Jesús Pérez González-Rubio con CongRep (artículo 23 inciso 2 Ley 58/1985). 
metodológico de las mismas ${ }^{27} \mathrm{o}$ bien por la forma de presentar la información ${ }^{28}$ pueden constituirse en una herramienta de manipulación y no de desarrollo de los fines enunciados anteriormente. Por ello, la Corte Constitucional ha establecido que las encuestas electorales son un ámbito material de protección del derecho fundamental a difundir información, el cual está limitado por el criterio de veracidad e imparcialidad. ${ }^{29}$ Este límite, a su vez, se desarrolla mediante un conjunto de reglas y subreglas.

\section{Reglas y subreglas en materia de reglamentación de encuestas electorales}

La reglamentación del derecho a diseñar, implementar y difundir encuestas electorales se rige por dos reglas esenciales diseñadas por la Corte Constitucional. La primera consiste en que las encuestas no pueden ser manejadas al arbitrio absoluto de personas o empresas que las realizan ni ser interpretadas tendenciosamente por los medios de comunicación, ${ }^{30}$ pues ello implica una violación del límite - aunque la Corte Constitucional lo denomina núcleo esencial— de información veraz e imparcial; mientras que la segunda regla consiste en que la reglamentación de las encuestas electorales son de reserva legal, conforme al artículo 152 literal c en concordancia con el artículo 265 numeral 6 (anteriormente numeral 5) de la Constitución. ${ }^{31}$

\section{Subreglas competenciales}

De acuerdo a la regla de reserva legal, la Corte Constitucional ha sostenido que la regulación de las encuestas electorales es una reserva de ley estatutaria. ${ }^{32}$ Esta subregla se debe a que, de acuerdo con la interpretación hecha por la Corte Constitucional, las encuestas electorales hacen parte de las funciones electorales, entendidas como todos aquellos aspectos permanentes para el ejercicio adecuado de las funciones democráticas por los ciudadanos — derechos fundamentales democráticos-, inclusive si estos aspectos sean considerados, en apariencia, como potestades menores o aspectos puramente técnicos, pero que tienen efectos determinantes en la dinámica electoral.

27. Sentencia de constitucionalidad de CongRep (proyecto de ley estatutaria 216/2005, Cámara, 235/2005, Senado).

28. Sentencia de Jesús Pérez González-Rubio con CongRep (artículo 23 inciso 2 Ley 58/1985); sentencia de constitucionalidad de CongRep (proyecto de ley estatutaria 11/1992, Cámara, 348/1993, Senado).

29. Sentencia de Jesús Pérez González-Rubio con CongRep (artículo 23 inciso 2 Ley 58/1985).

30. Sentencia de constitucionalidad de Jesús Pérez González-Rubio con CongRep.

31. Sentencia de constitucionalidad de CongRep (proyecto de ley estatutaria 11/1992, Cámara, 348/1993, Senado).

32. Sentencia de constitucionalidad de Jaime Orlando Santofimio y otros con CongRep (Ley 84/1993), Corte Constitucional de Colombia, rol C 145/1994, expedientes D-489 y otros. 


\section{Subreglas materiales}

En cuanto a la regla de limitación de las encuestas electorales, la Corte Constitucional ha sostenido, como subregla esencial, que la reglamentación debe enfocarse en desarrollar los derechos fundamentales - a diseñar, implementar y difundir encuestas electorales-, y no en suspender o desconocer los mismos. ${ }^{33}$ Cómo distinguir entre el desarrollo del derecho fundamental y la suspensión y el desconocimiento ha sido una tarea que la Corte Constitucional ha desarrollado en escenarios concretos.

El primer escenario consiste en la reglamentación del ámbito personal de aplicación. De acuerdo con la línea jurisprudencial de la Corte Constitucional, es legítimo establecer condiciones especiales sobre las personas o entidades encargadas de la realización de encuestas, pues ello garantiza, por una parte, la idoneidad técnica de las encuestas y, por otra, el manejo responsable, profesional, veraz y neutral que se recopila. ${ }^{34}$

El segundo escenario consiste en la metodología empleada por las personas o entidades encargadas de la realización de encuestas. En este caso, la Corte Constitucional establece dos grupos de subreglas. El primer grupo hace referencia a los medios que puede elegir la persona o entidad que realiza la encuesta. De acuerdo con la Corte Constitucional, la persona o entidad encuestadora no tiene prohibido elegir metodologías que permitan medir con mayor amplitud y en otros estratos sociales la intención electoral. Asimismo, la Corte Constitucional determinó que la realización de encuestas a través de internet no constituye una vulneración de derechos o principios fundamentales, sino que, por el contrario, ella garantiza el derecho fundamental de otras personas a expresar su opinión mediante las encuestas. El segundo grupo hace referencia al modo de elaboración de preguntas. De acuerdo con la Corte Constitucional, las preguntas deben estar diseñadas de forma tal que no distorsionen la voluntad del electorado. Asimismo, faculta al Consejo Nacional Electoral para hacer seguimiento de las preguntas, siempre y cuando su ejercicio sea de control y no de formulación. ${ }^{35}$

El tercer escenario hace referencia a la publicación de las encuestas. Aquí, bajo el argumento de transparencia democrática y responsabilidad social de las personas y entidades encuestadoras, construye dos subreglas sobre la publicación y presentación de resultados de las encuestas. La primera consiste en que, para garantizar el conocimiento mínimo de la calidad de la encuesta, así como la identificación del responsa-

33. Sentencia de constitucionalidad de Jesús Pérez González-Rubio con CongRep.

34. Sentencia de constitucionalidad de CongRep (proyecto de ley estatutaria 216/2005, Cámara, 235/2005, Senado).

35. Sentencia de constitucionalidad de CongRep (proyecto de ley estatutaria 216/2005, Cámara, 235/2005, Senado). 
ble de la encuesta, se pueden establecer condiciones sobre la publicación y difusión de encuestas, especialmente mediante la presentación de datos de identificación (encargado de la elaboración, preguntas elaboradas, candidatos por los cuales se indagó, etcétera)..$^{36}$ La segunda consiste en que los medios de comunicación no pueden interpretar tendenciosamente los resultados obtenidos en las encuestas. ${ }^{37}$

El cuarto escenario consiste en el tiempo de restricción de publicación de encuestas. La Corte Constitucional sostiene, como subregla, que el ciudadano debe tener un tiempo para poder reflexionar, sin influencia externa alguna, sobre la decisión que tomará en las urnas..$^{38}$ En virtud de esta subregla, la Corte Constitucional ha establecido otras dos. La primera consiste en que el Estado está facultado para restringir la realización y publicación de encuestas en el día de las elecciones ${ }^{39}$ y por un tiempo; ${ }^{40}$ la segunda regla - que podría considerarse un límite al límite-consiste en que ese tiempo debe ser prudencial, es decir, de pocos días, pues de lo contrario se estaría ante un ejercicio de censura. ${ }^{41}$ En el caso más reciente (2005), la Corte Constitucional estableció que un plazo prudencial podría entenderse como una semana.

\section{Método de proporcionalidad aplicado a la reglamentación de encuestas electorales}

La creación de las reglas anteriores a través de la jurisprudencia de la Corte Constitucional no fue, sin embargo, pacífica o uniforme. Al revisar la línea de tiempo, podría decirse que existió un cambio fundamental en el razonamiento de la Corte Constitucional. Dicho cambio se concreta en la concepción del derecho fundamental.

En el primer fallo en materia de encuesta electorales, la Corte Constitucional aplicó el método de proporcionalidad bajo el eje gravitacional del derecho fundamental a la libertad de información. Ello se reflejó en que, durante las primeras sentencias, la Corte Constitucional no enunció en momento alguno las funciones electorales, sino que empleó el método de interpretación por bloque de constitucionalidad, para establecer dos máximas: a) las encuestas electorales son un ámbito material de protección de la libertad de información, y b) sus límites se encuentran en la transmisión de información veraz, a través del empleo de metodologías y prevención de tergiver-

36. Sentencia de constitucionalidad de CongRep (proyecto de ley estatutaria 216/2005, Cámara, 235/2005, Senado).

37. Sentencia de constitucionalidad de Jesús Pérez González-Rubio con CongRep.

38. Sentencia de constitucionalidad de Jesús Pérez González-Rubio con CongRep.

39. Sentencia de constitucionalidad de CongRep (proyecto de ley estatutaria 11/1992, Cámara, 348/1993, Senado).

40. Sentencia de constitucionalidad de CongRep (proyecto de ley estatutaria 216/2005, Cámara, 235/2005, Senado).

41. Sentencia de constitucionalidad de Jesús Pérez González-Rubio con CongRep. 
saciones. En palabras de la Corte Constitucional:

Los medios de comunicación social, como titulares del derecho de informar, y la opinión pública, como titular del derecho a la información, tienen derecho a conocer y difundir la receptividad que entre la población tengan los programas ideológicos y la acción de los candidatos a los cargos de autoridad política, máxime en los momentos en que estas informaciones revisten la mayor importancia, como son las vísperas de una elección. Debe reconocerse que en una democracia moderna, uno de los medios más adecuados para este propósito es, precisamente, el de las encuestas de opinión. ${ }^{42}$

Al tener como eje gravitacional el derecho fundamental a la información, la Corte Constitucional se detuvo, básicamente, en los pasos de finalidad y necesidad de la acción de reglamentación de las encuestas electorales. Al estudiar el artículo 23 inciso primero de la Ley 58 de 1958 - que prohibía la realización y publicación de encuestas con treinta días de anticipación a las elecciones-, la Corte Constitucional fue categórica y sostuvo que no existe fundamentación alguna para prohibir la expresión de los encuestados en asunto público. ${ }^{43}$ En otras palabras, la Corte Constitucional sostuvo la ausencia de un fin legitimo ${ }^{44}$ — tanto mediato como inmediato-, que le permitiese al Estado reglamentar las encuestas, especialmente de prohibir su elaboración y divulgación dentro de los treinta días anteriores a las elecciones, pues

es una discriminación, un acto que impide, por una parte, que a la opinión pública se le informe de algo que le interesa legítimamente, y por otra, a los medios de comunicación ejercer su derecho a informar, esto es, a transmitir y difundir oportunamente las noticias de que dispone. ${ }^{45}$

Está postura categórica se morigeró un poco en el fallo posterior. En el proyecto de ley que se presentó después de la declaratoria de inconstitucionalidad de las

42. Sentencia de constitucionalidad de Jesús Pérez González-Rubio con CongRep.

43. Sentencia de constitucionalidad de Jesús Pérez González-Rubio con CongRep.

44. «No hay una fundamentación válida para prohibir que se exprese la opinión de los encuestados en un asunto público, y cuya divulgación no atenta contra el orden público, la intimidad o el bien común. Además, dada la naturaleza de la democracia participativa, la divulgación de encuestas electorales es asunto de interés general. Al ser de interés general el conocimiento de la opinión sobre los hechos que reflejan las encuestas, la información es debida, dada la prevalencia del interés general; por tanto, su restricción absoluta por el término de treinta días antes de la jornada electoral se torna en injusta, inconveniente e inoportuna, pues es un contrasentido que en el momento en que se requiere de mayor información, como capacitación previa para la decisión política de los electores, se les prive del conocimiento de un factor de interés, cual es la opinión de un sector de la sociedad, porque supone una restricción que riñe con la esencia de la participación de la comunidad en los asuntos públicos». Sentencia de constitucionalidad de Jesús Pérez González-Rubio con CongRep.

45. Sentencia de constitucionalidad de Jesús Pérez González-Rubio con CongRep. 
prohibición y elaboración de encuestas electorales dentro los treinta días anteriores, el Congreso planteó tres reglas: a) la obligación de publicar los datos técnicos de elaboración de la encuesta; b) la prohibición de elaborar y difundir encuestas dentro de los treinta días anteriores a la elección, y c) la prohibición de elaborar o difundir encuestas el día de las elecciones.

Respecto a la segunda regla, la Corte Constitucional sostuvo la regla planteada en el primer fallo. ${ }^{46}$ Sin embargo, las primera y tercera regla le permitieron morigerar su posición categórica. En la primera regla, la Corte Constitucional no mantuvo como eje gravitacional la libertad de información, sino la función electoral. Al trabajar las encuestas en este eje, reconoció la facultad de intervención legislativa, así como un fin legítimo inmediato. Éste consistía en prevenir la manipulación informativa, lo cual conduce, como sostuvo la misma Corte en su primer fallo, a reconocer el fin mediato de información veraz. Al tener en colisión una función electoral y el derecho a recibir información veraz, la Corte Constitucional otorgó un peso abstracto y concreto grave a éste, así como un peso abstracto grave y concreto medio a la función electoral. En cuanto al nivel de certeza, le otorgó un grado de cierto a la prevención de información manipulada. Esto permite tener como fórmula:

$$
G_{l, k}=\frac{4_{l} 2_{l} 2_{l}}{4_{k} 4_{k} 4_{k}}
$$

donde $l$ es la función electoral, mientras que $k$ es la necesidad de garantizar el derecho fundamental a recibir información veraz. En palabras de la Corte Constitucional:

La Constitución Política contempla expresamente la existencia de normas legales sobre publicidad y encuestas de opinión política (artículo 265-5). Abona la exequibilidad del primer inciso del artículo, adicionalmente, el adecuado ejercicio de la mencionada atribución legislativa. No se remite a duda que la correcta estimación del resultado de una encuesta, indispensable para ponerle coto efectivo a su instrumentación manipulativa, depende de los elementos que la norma exige se publiquen conjuntamente con sus conclusiones y hallazgos. ${ }^{47}$

En cuanto a la restricción de elaboración y difusión de encuestas en el día de las elecciones, la Corte Constitucional mantuvo el eje gravitacional en la función electoral. Sin embargo, el derecho fundamental que contrapuso no fue el de información

46. Sentencia de constitucionalidad de CongRep (proyecto de ley estatutaria 11/1992, Cámara, 348/1993, Senado).

47. Sentencia de constitucionalidad de CongRep (proyecto de ley estatutaria 11/1992, Cámara, 348/1993, Senado). 
veraz, sino el derecho fundamental al voto. Como peso abstracto, el cual consideró grave, la Corte Constitucional reconoció el valor del voto en un sistema democrático; como peso concreto, consideró la necesidad de proteger al elector de cualquier influencia externa y, así, el voto secreto. En cuanto al nivel de seguridad, la Corte Constitucional reconoció la necesidad de acallar las voces. Ello permite el empleo similar de la fórmula:

$$
G_{l, k}=\frac{4_{l} 2_{l} 2_{l}}{4_{m} 4_{m} 4_{m}}
$$

donde $m$ es el derecho al voto. En palabras de la Corte Constitucional:

Es evidente que la divulgación de encuestas y proyecciones sobre el comportamiento electoral el día de las elecciones puede interferir el desarrollo normal y espontáneo del respectivo certamen y dar lugar a equívocos o informaciones que desorientan o desalientan a los votantes. El día de las elecciones en el que los ciudadanos ejercen secretamente su derecho al sufragio (Constitución Política, artículo 258) y se define el rumbo democrático del país, deberán acallarse todas las voces que no sean la voz del pueblo. Por lo expuesto, la ley que regula la publicidad y las encuestas electorales, puede introducir la prohibición analizada..$^{48}$

En el último fallo, la Corte Constitucional se enfrentó a un nuevo escenario y un cambio normativo. El nuevo escenario consistía en la posibilidad que tendría el presidente de la República a ser relecto en las elecciones presidenciales siguientes. Ello implicó un cambio de razonamiento, pues todas las herramientas electorales deberían estar encausadas a la protección del derecho a la igualdad de los contendores. En el caso concreto, la Corte Constitucional aprovechó esta situación para alterar su obiter dicta y plantear que las encuestas electorales, además de ser una función electoral, son una herramienta de imagen del candidato. Según la Corte Constitucional:

Las encuestas son herramientas fundamentales para medir la imagen personal del político - reflejada en los eslóganes de la campaña, en los afiches, etcétera-, la aceptación de su programa de gobierno y la popularidad de su trato con la comunidad. Las encuestas delimitan los grupos sociales a los cuales debe dirigirse con mayor ahínco el candidato e identifican los temas de la propuesta política que deben reforzarse. ${ }^{49}$

En cuanto las reglas concretas de las encuestas electorales, el Congreso reiteró la

48. Sentencia de constitucionalidad de CongRep (proyecto de ley estatutaria 11/1992, Cámara, 348/1993, Senado).

49. Sentencia de constitucionalidad de CongRep (proyecto de ley estatutaria 216/2005, Cámara, 235/2005, Senado). 
norma de difusión de los datos técnicos de elaboración de encuestas. Por ello, el razonamiento de la Corte Constitucional no fue diferente al hecho en 1994. Sin embargo, el Congreso cambió su postura respecto de la prohibición de difundir encuestas antes de las elecciones, y propuso una restricción no de treinta, sino de siete. Ello le permite a la Corte Constitucional separarse del argumento categórico de inexistencia de fin legítimo, para ahondar en la necesidad y la proporcionalidad en estricto sentido. De acuerdo a la Corte Constitucional:

Atendiendo a que la restricción en este caso no es de treinta días, sino de siete, la Corte Constitucional considera que el precedente jurisprudencial no es aplicable, pues evidencia que la restricción al derecho de información no es desproporcionada. Por el contrario, entiende de la disposición se ajusta a la Carta y es proporcionada al fin perseguido, al permitir a los electores contar con una semana de reflexión para definir, sin la presión de los resultados de las encuestas, su preferencia electoral..$^{\circ 0}$

Al permitir el avance en el examen, la Corte Constitucional elaboró un razonamiento en el cual el derecho fundamental protegido es el derecho al voto informado. Él requiere, como peso concreto, que la información brindada no sea solamente veraz, sino también imparcial y, si las encuestas permiten también medir la imagen del candidato, ello podría implicar acciones por parte del mismo para desviar en los momentos finales al electorado. Por ello, la Corte Constitucional le otorgó un pesó concreto grave y reconoció la necesidad de garantías. La única diferencia consistió en que el derecho restringido fue el de recibir información, lo cual implicó un empate en la fórmula:

$$
G_{l, k}=\frac{4_{l} 4_{l} 4_{l}}{4_{m} 4_{m} 4_{m}}
$$

Ello no significó, sin embargo, que la Corte Constitucional fallase a favor del derecho fundamental a recibir información, sino que aplicó el principio pro legislatore, según el cual un empate en el ejercicio de proporcionalidad estricto implica la constitucionalidad de la norma. En palabras de la Corte Constitucional:

En este sentido, la Corte considera que los dos pronunciamientos anteriores de la Corporación no son aplicables a la norma objeto de estudio, pues contenían una restricción de mayor duración que la que ahora se impone. En el artículo 28 del proyecto de ley, la imposibilidad de publicar encuestas electorales se restringe a una semana antes de las elecciones, por lo que no constituye una decisión que sacrifique

50. Sentencia de constitucionalidad de CongRep (proyecto de ley estatutaria 216/2005, Cámara, 235/2005, Senado). 
injustamente el derecho a la información de los electores. ${ }^{51}$

En síntesis, si bien la Corte Constitucional sostuvo una postura inicial en torno a la reglamentación de las encuestas, ella varió progresivamente el nivel de protección, a través de los ejes gravitacionales de función electoral y voto informado.

\section{Conclusiones y discusiones en torno a la situación actual de la reglamentación de encuestas electorales}

La siguiente pregunta consiste en si el proyecto de ley 114/2015 (Senado) se ajusta a estos criterios jurisprudenciales. Si se revisa con detenimiento, podría encontrarse una armonía generalizada entre los fines, así como la mayoría de las reglas del proyecto, con las reglas y subreglas establecidas por la línea jurisprudencial de la Corte Constitucional. Por ejemplo, si se revisa el problema planteado por la Comisión primera del Senado -el desdibujamiento de las encuestas electorales, entendidas ahora como mecanismo de manipulación de la intención de voto ciudadano (proyecto de ley 114 de 2015, por medio de la cual se crean disposiciones para la realización y divulgación de encuestas electorales, en cargos de elección popular, y se dictan otras disposiciones, página3) - , coincide con el problema hipotético planteado por la Corte Constitucional desde sus inicios. Asimismo, la Comisión primera del Senado identifica correctamente el límite esencial del derecho a realizar encuestas en el concepto de información veraz (proyecto de ley 114, página 2), reconocido también por la Corte Constitucional.

Por otra parte, si se revisa el articulado propuesto por la Comisión primera, varias de las normas contenidas en ellos concuerdan con las reglas y subreglas establecidas en la línea jurisprudencial de la Corte Constitucional. Por ejemplo, el artículo 4 respeta los aspectos competenciales de los distintos órganos estatales; el artículo 5 recoge la tradición constitucional - especialmente algunos criterios de la sentencia C 1153/2005-, y los artículos 6, 7 y 8 desarrollan las reglas establecidas para el diseño, realización y publicación de encuestas - aunque no cita expresamente a la Corte Constitucional, sus fundamentos son similares (proyecto de ley 114, página 3)-.

Sin embargo, el proyecto de ley deja algunos interrogantes que es necesario resolver en el trámite del mismo: i) naturaleza de la ley; ii) el aparente conflicto entre el artículo 9 literal b y literal d, y iii) la prohibición de realizar encuestas a través de la internet.

El proyecto de ley menciona en sus considerandos que existe reserva legal en materia de reglamentación de las encuestas electorales (proyecto de ley 114, página 2).

51. Sentencia de constitucionalidad de CongRep (proyecto de ley estatutaria 216/2005, Cámara, 235/2005, Senado). 
Sin embargo, no hace un estudio sobre la necesidad de que la ley se tramite bajo las reglas de ley estatutaria, como lo estableció la línea jurisprudencial de la Corte Constitucional. Tampoco enuncia el título del proyecto que éste verse sobre una ley estatutaria, lo cual podría llevar a la confusión de pensar que, o bien la ley se trabaja actualmente bajo las reglas de ley ordinaria, o bien que hubo una omisión tanto en la parte del título como en la parte motiva. Bajo el primer escenario, el proyecto, que es interesante y necesario, se vería viciado por cuestiones de procedimiento y, por tanto, pesaría sobre él una declaratoria de inexigibilidad. Bajo el segundo escenario, sólo se estaría ante una omisión, la cual puede ser corregida sin mayor complicación.

El segundo interrogante se encuentra en la redacción del artículo 9 literales b y d. En el primer literal se establece la prohibición de realizar o publicar encuestas o sondeos la semana anterior a las elecciones de los cargos establecidos en el artículo 3, mientras que el segundo literal hace referencia a la prohibición, en cualquier caso, de realizar y publicar encuestas, sondeos o proyecciones electorales diez días antes de los comicios. Si se revisa con detenimiento, podría encontrarse una aparente contradicción, pues podría pensarse que existen dos prohibiciones simultáneas sobre el mismo tema. Para ello, se pueden plantear tres alternativas.

La primera consiste en pensar que existe una relación lex generalis lex specialis en materia de encuestas. La norma general implicaría que en cualquier elección (referendos, plebiscitos, consultas populares, etcétera) estaría prohibida la realización encuestas, sondeos y proyecciones electorales dentro de los diez días previos a los comicios, mientras que la norma especial establecería que sólo en los casos de elección de cargos de representación (Presidencia, Congreso, gobernaciones, asambleas, alcaldías y concejos) la prohibición sería de siete días. Esta lectura presentaría algunos inconvenientes a futuro. El primero consistiría en establecer cuál es el criterio diferenciador para sostener que en unas elecciones la prohibición es de siete y en otra de diez; la segunda es si se presentó una modificación tácita a la ley de mecanismos de participación ciudadana, y la tercera es si se puede entender proporcional el lapso de diez días.

La segunda alternativa consistiría en que el artículo 9 literales b y d rigen únicamente para las encuestas electorales propias del proyecto de ley. Esta interpretación crearía más confusiones, pues tendría que determinarse cuándo es aplicable el literal b y cuándo el literal d.

La tercera alternativa sería eliminar el artículo 9 literal d.

El tercer interrogante consiste en la prohibición de realizar encuestas electorales a través de internet. El motivo plasmado por la Comisión primera es eliminar aquellas metodologías que no impliquen un acercamiento directo con la ciudadanía y, por tanto, que no permitan comprobar la capacidad de las personas o si éstas comprenden las preguntas y responden adecuadamente a ella (proyecto de ley 114, página 3). Sin embargo, esta prohibición presenta algunos problemas. El primero consiste en 
una contradicción entre la intención del Legislador y la subreglas metodológicas de diseño. Como se enunció anteriormente, la Corte Constitucional sostiene que las personas o entidades que realizan encuestas gozan de un cierto margen de discrecionalidad para elegir el modelo y mecanismo, siempre y cuando este modelo garantice una participación de todos los actores sin importar su estrato social o ubicación geográfica. Junto a esta subregla, podría establecerse como segundo problema la desprotección de personas que deseen intervenir en el proceso de opinión política. De acuerdo con la Corte Constitucional, las encuestas no sólo son un mecanismo de trazo de tendencias, sino que también constituyen el desarrollo de un derecho fundamental, a saber, el derecho de la persona a opinar sobre un candidato o programa político. Si se excluyera el mecanismo de internet, se excluirían a las personas que, a través del mecanismo, podrían expresar su opinión..$^{52}$ Este sería el caso de quienes viven fuera del país y tienen, como alternativa, la manifestación de opiniones a través de internet.

El proyecto de ley de reglamentación de encuestas electorales es un instrumento idóneo, que se ciñe a los lineamientos generales establecidos por la jurisprudencia constitucional. Sin embargo, es necesario revisar algunos aspectos, tales como la naturaleza de la ley, la prohibición de encuestas por internet y los límites temporales de las encuestas.

\section{Referencias}

BERnAL, Carlos (2009). El neoconstitucionalismo y la normatividad del derecho. Bogotá: Universidad Externado.

BRECKWOLDT, Maike y Michael Kleiber (2013). «Grundrechtskombinationen: $\mathrm{Zu}$ Struktur und Rationalität der Abwägung bei Prinzipienmehrheiten». En Matthias Klatt (editor), Prinzipientheorie und Theorie der Abwägung. Heidelberg: Mohr Siebeck.

Corzo Sosa, Edgar (2007). «Las encuestas electorales y los derechos fundamentales: Una primera reflexión». Cuestiones Constitucionales, 16: 71-87. Disponible en http://bit.ly/2loEtlh.

FernÁndeZ SANABRIA, Alejandro (2010). «La prohibición de publicar encuestas electorales como una limitación desproporcionada e ilegítima de la libertad de expresión e información en Costa Rica». Derecho Electoral, 10: 1-50. Disponible en http://bit.ly/2lnCnlO.

Gálvez MuÑoz, Luis (2000). «Organismos de sondeos, encuestas electorales y derecho». Estudios Políticos, 110: 97-121. Disponible en http://bit.ly/2lnDbHm.

Hernández VALdeZ, Alfonso (2013). «Efectos, errores y regulación de las encuestas

52. Sentencia de constitucionalidad de CongRep (proyecto de ley estatutaria 216/2005, Cámara, 235/2005, Senado). 
preelectorales: Una política de transparencia para el caso mexicano». Confines, 9 (18): 59-85. Disponible en http://bit.ly/2lqwnse.

IBLER, Martín (2004). «Importantes aspectos de la historia y dogmática de los derechos fundamentales en Alemania». Iusta, 2 (21): 15-25. DOI: 10.15332/s190o0448.2004.0021.01.

López Medina, Diego Eduardo (2014). El derecho de los jueces. Bogotá: Legis.

Mateos, Araceli y Alberto Penadés (2013). «Las encuestas electorales en la prensa escrita (2008-2011): Errores, sesgos y transparencia». Metodología de Encuestas, 15: 99-119. Disponible en http://bit.ly/2lozAZD.

Moreno, Alejandro, Rosario Aguilar y Vidal Romero (2011). «La precisión de las encuestas electorales en México: un análisis de las fuentes de error». Revista Legislativa de Estudios Sociales y de Opinión Pública, 4 (8): 7-45.

Nicodemo, Pasquale (2007). «iSon confiables las encuestas electorales en Venezuela?». Comunicación, 140: 60-68. Disponible en http://bit.ly/2DtjgOG.

Ortiz Lazcano, Assael (2006). «Acerca del lugar de la entrevista en las encuestas electorales». Cultura y Política, 25: 177-209. Disponible en http://bit.ly/2DqAlc4.

Pacheco Luna, Carolina y Mauricio Velásquez Posada (2006). «Las encuestas electorales y su regulación». Derecho Comparado de la Información, 8: 53-47.

Pavía, José y Belén García-Cáceres (2012). «Una aproximación empírica al error del diseño muestral en las encuestas electorales del CIS». Metodología de Encuestas, 14: 45-62. Disponible en http://bit.ly/2DqSzda.

Pieroth, Bodo, Bernard Schlink, Thorsten Kingreen y Ralf Poscher (2013). Grundrechte: Staatsrecht II. 29. ${ }^{\mathrm{a}}$ ed. Karlsruhe: C. F. Müller.

\section{Sobre el autor}

Jorge Ricardo Palomares García es abogado, magíster en Derecho y candidato a doctor en Derecho de la Universität Konstanz de Alemania. Profesor asociado del área de Derecho Público de la Universidad Libre, seccional Bogotá, Colombia, donde es miembro del observatorio de intervención ciudadana constitucional, investigador asociado del grupo de investigación en derecho constitucional nacional y comparado y regente de las cátedras Derecho Constitucional General y Jurisprudencia constitucional.Su correo electrónico es jorger.palomaresg@unilibrebog.edu.co. 
La Revista de Derecho Público es publicada, desde 1963, dos veces al año por el Departamento de Derecho Público de la Facultad de Derecho de la Universidad de Chile. Su propósito es la difusión de los avances del derecho público nacional e internacional y la socialización de artículos de investigación inéditos tanto de la comunidad académicas nacional e internacional.

DIRECTORA

Ana María García Barzelatto

SECRETARIO DE REDACCIÓN

Felipe Peroti Díaz

(fperoti@derecho.uchile.cl)

SITIO WEB

revistaderechopublico.uchile.cl

CORREO ELECTRÓNICO

publico@derecho.uchile.cl

LICENCIA DE ESTE ARTÍCULO

Creative Commons Atribución Compartir Igual 4.0 Internacional

La edición de textos, el diseño editorial

y la conversión a formatos electrónicos de este artículo

estuvieron a cargo de Tipográfica

(www.tipografica.cl). 